\section{Toward Higher Laws: Henry David Thoreau's Concept of Animal Rights in Walden}

\section{Tang Wei}

School of Foreign Languages, Nanjing University, Nanjing, China

Email: tangwei@ncu.edu.cn

\section{Abstract:}

Though living in the age of Industrialization when the concept of anthropocentricism was prevalent and not a hardcore vegetarian, Thoreau challenged the anthropocentric view of human being's condescending superiority over animals in Walden. Not only does Thoreau view non-human animals as subjects possessing their own consciousness and sentience, he also regards a consummation of one's spirituality involves admitting and understanding of one's inner animality so as to inhibit his savage instinct to hunt or kill animals for food, on the grounds that animals are sentient to feel pain and sufferings and animal food is both unclean and degenerated. Therefore, Thoreau's humanity to non-human animals inspires and will inspire his modern readers to show more respect for non-human animals and lead them to aspire for a higher stage in their spiritual development. It is in this sense that Thoreau's concept of animal rights in Walden shakes the solid foundation of anthropocentricism and approximates, if not pioneers, the modern concept of animal rights.

Keywords:

Walden; animal rights; consciousness; sentience; vegetarianism

\section{Introduction}

Henry David Thoreau's classic work Walden has won him high acclaim for passing the virtue of self-reliance and self-sufficiency, epitomized by his solitude experience for more than two years in a cabin he built near the Walden Pond, onto myriads of his readers. As a great transcendentalist, naturalist and environmentalist, Thoreau always aspired to acquire a more objective understanding of society through personal introspection by immersing himself in nature.

\section{Review of Literatures}

Since the explosion of environmentalism in the late 1960s and 1970s, the nature writing and the idea of environmental conservation in Thoreau's Walden and other works have come into the academic concern of many critics who have conducted a series of researches from the perspective of ecocriticism - an interdisciplinary study of literature and environment. Representative among these critics are Leo Marx, Donald Worster and Lawrence Buell. Leo Marx's monograph The Machine in the Garden: Technology and the Pastoral Ideal in America (1964) asserts that Thoreau's works embody the Western tradition of pastoral culture, regard modern industry as the machine in the garden, and hence reveal the corrosion of agriculture by modern industrialization and commercialization. Donald Worster's Nature's Economy: A History of Ecological Ideas (1977) includes a detailed introduction of Thoreau's ecological ideas and regards Thoreau as an active field ecologist, a nature philosopher beyond our era. Lawrence Buell's The Environmental Imagination: Thoreau, Nature Writing, and the Formation of American Culture regards Walden (1995) as a quest for 


\section{Linglit Journal: Scientific Journal of Linguistics and Literature \\ ISSN: 2774-4523 (Online), 2774-4515 (Print)}

Vol. 2, No. 1, March 2021, Page: 25-32

Email: linglitjournal@gmail.com

greater environmental awareness, an impetus and guide for a new vision of environmental writing and a new way of conceiving the relation between human imagination and environmental actuality in the age of industrialization. Edward $\mathrm{O}$ ' Wilson, the scientist and naturalist, called Thoreau "the father of environmentalism". Bill McKibben once remarked, "At the close of the 20 th century, it is most crucial to read Walden as a practical environmentalist's volume, and to search for his heirs among those trying to change our relation to the planet."

However, while studies are abundant in revealing the tendency of environmentalism and anti-anthropocentricism in Walden, they often take a cursory view at Thoreau's advocacy of animal rights or make no discrimination between it and Thoreau's concept of nature. While proponents of animal rights share the common ground of anti-anthropocentricism with ecocritics, they focus more on a bolder and more challenging idea that some, or all, non-human animals are entitled to the possession of their own lives, and that their most basic interests such as an interest in not suffering - should be afforded the same consideration as the similar interests of human beings.

\section{Research Methods}

The anthropocentric view often presupposes a dichotomy of mankind and animals which subordinates the latter to the former. Mankind has always been regarded as the only sensible creature with soul and consciousness and hence is seen superior to all other creatures on the globe, which is epitomized by the Ancient Greek philosopher Protagoras' statement "man is the measure of everything" and by verse 1:26 in the Book of Genesis - "And God said, Let us make man in our image, after our likeness: and let them have dominion over the fish of the sea, and over the fowl of the air, and over the cattle, and over all the earth, and over every creeping thing that creepeth upon the earth." While men are regarded as the owner of the world, non-human animals have often been seen as irrational objects possessing no soul and hence no consciousness or sentience, which is represented in the philosophy of Descartes who despised animals as mere "machines, automata" and the Christian doctrine which chants that animals do not have immortal souls.

Since the Industrial Revolution, human beings have been exploiting so immoderately and greedily from nature that environmental problem has escalated into a global ecological crisis. Suffering from the disastrous results of a worsening ecosystem, mankind begins to realize that the globe we live on is shared by a variety of species and we could not only care about our own interests. Instead of regarding animals as inferior, immoral and inadequate to assume rights, many environmentalists have already begun to advocate the equal rights of animals with human beings. They maintain that animals are creatures equal to human beings and hence they should hold the same rights, including moral rights, as human beings and no longer be viewed as property, or used as food, clothing, research subjects, entertainment, or beasts of burden. Among the most leading advocators of animal rights are Peter Singer and Tom Regan. Both of them reject the anthropocentric view that animals are irrational and insentient, insisting that animals also possess consciousness and sentience which help them to feel pain and suffering, and hence are qualified to have the moral rights of not being killed or used by mankind for any instrumental value. Furthermore, the text of the "Universal Declaration of Animal Rights" has been adopted from the International League of Animal Rights and Affiliated National Leagues in the course of an International Meeting on Animal Rights which took place in London from 21st to 23rd September 1977, and declared by UNESCO on 15th October 1978 as an affirmation of animal rights. 
Under such circumstances, a number of researchers have taken notice of Thoreau's relation to environmental ethics and animal rights. For instance, Philip Cafaro's Thoreau's Living Ethics: Walden and the Pursuit of Virtue (2004) shows Thoreau not only anticipating recent arguments for wild nature's intrinsic value, but also demonstrating how a personal connection to nature furthers self-development, moral character, knowledge, and creativity. Furthermore, Thoreauvian Modernities: Transatlantic Conversations on an American Icon (2013) integrates sixteen essays by researchers from the United States and Europe together which reveal Thoreau's relevance to a number of fields, including science, philosophy, aesthetics, environmental ethics, political science, and animal studies.

The purpose of this article is to ascertain Thoreau's concept of animal rights. Though living in the age of Industrialization when the concept of anthropocentricism was prevalent and not a hardcore vegetarian, Thoreau challenged the anthropocentric view of human being's condescending superiority over animals in Walden. Not only does Thoreau view non-human animals as subjects possessing their own consciousness and sentience, he also regards a consummation of one's spirituality involves admitting and understanding of one's inner animality so as to inhibit his savage instinct to hunt or kill animals for food, on the grounds that animals are sentient to feel pain and sufferings and animal food is both unclean and degenerated. Therefore, Thoreau's humanity to non-human animals inspires and will inspire his modern readers to show more respect for non-human animals and lead them to aspire for a higher stage in their spiritual development. It is in this sense that Thoreau's concept of animal rights in Walden shakes the solid foundation of anthropocentricism and approximates, if not pioneers, the modern concept of animal rights.

\section{Results and Discussion}

\subsection{Animal's Consciousness and Sentience}

One prerequisite for the assertion of environmental ethics and animal rights is to abstain from the anthropocentric view and see non-human animals as subjects with their own consciousness, sentience and hence rights or "inherent value" like human beings. In Animal Liberation, Peter Singer rebuts the historically anthropocentric attitude to non-human animals that is "so deeply ingrained in our thought that we take it as an unquestioned truth" and tries to "shatter the complacency with which the attitude is held by a frontal attack" (2002:185). He sides with Jeremy Bentham in arguing that animals should have rights based on their ability to feel pain more than their intelligence. In The Case for Animal Rights, Tom Regan reprimands several kinds of traditional moral views which stress human's indirect duty to non-human animals such as the Cartesian view which regards non-human animals as irrational automata who have no sentience, and the Contractarian view which holds there is no direct relevance between nonhuman animals and morality on the ground that they are unable to comprehend and sign a contract.

In his lifetime, Thoreau displayed constant affection, compassion and respect to animals and furious rage at the cruel treatment of any animal. A scholar of ecology once said:

In his occasional reflections, Thoreau railed strongly against the human onslaught on wildlife because it seemed so unnecessarily driven by greed and hypocrisy and led to such an impoverished state of nature. The wholesale elimination of large native mammals, driven by such petty and ridiculous fads as the one for skunk fur that emerged from some nameless salon of couture in the spring of 1859, was singled out by Thoreau as an example of the woeful condition of humankind." (Foster, 2009:153) 
Edward Waldo Emerson, who was a friend of Thoreau when Edward was a young boy, recalled that Thoreau "felt real respect for the personality and character of animals" (Mott, 2005: xxvii). Edward also observed in his friend "the same mutual affection between human and animal companions - the same respect for the integrity and worth of the "lower animals" (Mott, 2005: xxvii).

In Thoreau's writings, non-human animals are often endowed with human demeanor or even emotions and regarded as rational subjects with their own individuality rather than lower objects that are bestial and irrational and of only instrumental value to human beings. To Thoreau, non-human animals not only behave like human beings, but also are subjects like human beings who possess their own consciousness and individuality. For instance, he regards "the foxes as 'rudimental burrowing men, still standing on their defence, awaiting their transformation;' while the dog is to the fox as the white man to the red. The horse appears to him as a human being in a humble state of existence, and the humane way in which the oxen behave when loosed from the yoke at evening affects him pathetically. The wild shaggy moose in the Maine forests are 'moose-men, clad in a sort of Vermont gray or homespun,' and he expressed respect even for the skunk, for its suggested resemblance to one of the human aborigines of the country" (qtd. in Salt et al, 2000:110). Thoreau also shows great awe and empathy for the psychic power of animals and even equates non-human animals with human beings as he exclaims in his journal for 12th December 1856: "Wonderful, wonderful is our life and that of our companions! That there should be such a thing as a brute animal, not human! and that it should attain to a sort of society with our race" (Mott, 2005:xxvii).

In Walden, there are frequent occasions on which Thoreau delineates animals as man-like subjects possessing their own consciousness. Animals around the pond are making sounds and music of mankind like poets and musicians. Owls scream "like mourning women their ancient ulu-lu", which is "truly Ben Jonsonian" and a "most solemn graveyard ditty, the mutual consolations of suicide lovers remembering the pangs and the delights of supernal love in the infernal groves" (Thoreau, 2004: 120-121). Thoreau even uses the pronoun "she" to personify a "hooting" owl who makes "the most melancholy sound in Nature as if she meant by this to stereotype and make permanent in her choir the dying moans of a human being, - some poor weak relic of mortality who has left hope behind, and howls like an animal, yet with human sobs, on entering the dark valley, made more awful by a certain gurgling melodiousness" (Thoreau, 2004:121). A frog is personified and caricatured as an alderman "with his chin upon a heart-leaf, which serves for a napkin to his drooling chaps, under this northern shore quaffs a deep draught of the once scorned water, and passes round the cup with the ejaculation tr-r-roonk, tr-r-roonk, tr-r-roonk!" (Thoreau, 2004:122-123). Likewise, a female partridge is personified as a protecting mother who "led her brood past my windows, from the woods in the rear to the front of my house, clucking and calling to them like a hen, and in all her behavior proving herself the hen of the woods" while the young birds are described as with "all intelligence seems reflected in them" and suggesting "not merely the purity of infancy, but a wisdom clarified by experience" (Thoreau, 2004:217). Therefore, it is obvious that Thoreau views non-human animals not as mere insensitive, irrational objects waiting to be killed or used by human beings, but as subjects who possess their own consciousness, emotion and wisdom.

Since Thoreau regards nonhuman animals as subjects possessing consciousness, he steps further to point out that they have sentience like human beings and can feel pain and suffering. In the Chapter of "Higher Laws", though Thoreau compliments hunting as a necessary part of education for boys, he only regards it as a tool to turn a boy to a "humane" man who will become aware of the sentience of animals and stop hunting. "No humane being, past the 
thoughtless age of boyhood, will want only murder any creature, which holds its life by the same tenure that he does. The hare in its extremity cries like a child" (Thoreau, 2004:204). Here, Thoreau holds an obvious anti-anthropocentric view in accord with modern assertions of animal rights which are based on the assumption that animals are sentient to feel pain and suffering like human beings. The hare cries only because it is conscious, sentient to feel the pain and suffering as human beings. Hence it is in this sense Thoreau utters ironically that his sympathies are not, like many people, directed only to human but also to non-human animals. "I warn you, mothers, that my sympathies do not always make the usual phil-anthropic distinctions" (Thoreau, 2004:204). In Philip Cafaro's view, the reason Thoreau used a hyphen inside the word 'philanthropic' to divide it into two parts and italicized the latter part is that "reserving all love and concern for humans - phil-anthropy, emphasis in the original - is both superficial, based on ignorance of what is below the surface, and selfish, an excuse for unjustified self-partiality" (Cafaro, 2004:141). Hence, it is apparent that Thoreau is announcing a view of antianthropocentricism here. To Thoreau, animals are creatures equal to human being. They have their own consciousness and sentience to feel pain and suffering.

\subsection{Animal Rights and Vegetarianism}

Both Peter Singer and Tom Regan regard non-human animals' consciousness and sentience to feel pain and suffering as the basis for them to assume moral rights, at least the moral rights of not being tortured or killed by human beings for instrumental values. Due to this, both of them staunchly advocate the concept of vegetarianism, regarding it as a necessary and obligatory boycott against mankind's cruelty to animals. In discussing whether animals have moral rights, Peter Singer applies Jeremy Bentham's utilitarian moral philosophy, which incorporates "the essential basis of moral equality into his system of ethics by means of the formula: "Each to count for one and none for more than one", to assert that "the basic element - the taking into account of the interests of the being, whatever those interests may be - must, according to the principle of equality, be extended to all beings, black or white, masculine or feminine, human or nonhuman." (Singer, 2002:5) Furthermore, he sides with Bentham on regarding "the capacity for suffering as the vital characteristic that gives a being the rights to equal consideration" (Singer, 2002:7). He then points out "the need for each one of us to stop buying the products of modern animal farming" and "vegetarianism is a form of boycott" since once vegetarians "have broken away from flesh-eating habits they can no longer approve of slaughtering animals in order to satisfy the trivial desires of their palates" (Singer, 2002:162). Likewise, though admitting it is difficult to draw a line between animals who have consciousness and sentience and who have not and also how much they have them, Tom Regan believes that we should at least view those "normal mammalian animals ... as psychophysical individuals who have an individual welfare ..." because they have not only consciousness and sentience but also "beliefs and desires, memory and a sense of the future, an emotional life, a kind of autonomy, intentionality and self-awareness" based on which Regan develops the notion of "subject-of-alife" as the true basis for ascribing "inherent values" and hence moral rights to all individuals, whether human or non-human (Regan, 2004:162-243). Regan then stands on the position of "the rights view", differing from the utilitarianism view, to assert that "vegetarianism is morally obligatory" (Regan, 2004:351).

If we are to read the sentence in "Higher Laws" which expresses Thoreau's compassion for the pitiful hare more carefully, we can find that Thoreau is no wonder holding a view of animal rights here because he argues for the hare's equal moral right of not being "murdered". The word "murder" has been used elsewhere by Thoreau to express his preference of putting non-human animals equal to human beings as moral subjects. In a letter of 16 February of 1847, he wrote: "I confess to a little squeamishness on the score of robbing their [birds'] nests, though 
I could easily go to the length of abstracting an egg or two gently, now and then, and if the advancement of science obviously demanded it might be carried to the extreme of deliberate murder" (Thoreau, 1974:175).

One category of animals that frequently comes to Thoreau's focus in his writings is fish. Not only he describes various fishes around Concord area in detail, but also bemoans the plight these fishes encounter along the course of industrial development. For instance, in his A Week on Concord and Merrimack Rivers, Thoreau sighs for the fact that shads and other fishes, once in great numbers in New England's rivers, are now often blocked by dams. He then moves further to argue for the virtue of fishes, which in Philip Cafaro's view is "one of the earliest explicit calls for a non-anthropocentric ethics" (Cafaro, 2004:141). Thoreau marvels, "Away with the superficial and selfish phil-anthropy of men, who knows what admirable virtue of fishes may be below low-water mark, bearing up against a hard destiny, not admired by that fellow creature who alone can appreciate it" (Thoreau 2014:37). Here, Thoreau clearly and resolutely makes explicit the moral attributes of fishes and praises their virtues which are "the characteristic qualities that make these species what they are" (Cafaro 2004:141).

With all these, Thoreau, though living in the age of industrial revolution, marks himself a pioneer of animal rights and environmental ethics, which leads to his partiality for vegetarianism. Though Thoreau occasionally ate fish and rare salt pork, Thoreau was, for most of his life, a staunch vegetarian according to Henry S. Salt, one of his biographers. Salt wrote, "His diet was fully as simple and economical as his clothing; his food, while staying at Walden, consisted of rice, Indian meal, potatoes, and very rarely salt pork, and his drink was water ... he had a strong preference at all times for a vegetarian diet, though he would occasionally catch a mess of fish for his dinner form Walden Pound ... during the greater part of his life he was a vegetarian in practice, and in several passages has made profession of his faith in the humanities of diet ..." (Salt, 2000: 44-111). In "Higher Laws", though admitting his hobby of fishing and hunting and his occasional diet of fish and meat, Thoreau regards it as only an "instinct" in him "which belongs to the lower orders of creation". He gradually gives up fishing, and feels a strong repugnance to animal food because "there is something essentially unclean about this diet and all flesh" (Thoreau, 2004:206).

\subsection{A Higher Spirituality}

Instead of insisting on advocating vegetarianism as a prerequisite and useful tool for the assertions of animal rights like Peter Singer and Tom Regan, Thoreau views vegetarianism, more philosophically, as an understanding and then abstinence of the instinctual, savage, lower "animality" to achieve "a higher spiritual life", which probably better persuades people to refrain from animal food.

Though Thoreau views hunting and fishing as a necessary part of education and meaningful entertainment for a young man, he doesn't mean to popularize it among the young. He only expects it to be a transition in the young man's individual development until he has "the seeds of a better life in him" and "distinguish his proper objects" (Thoreau, 2004:205). He believes that the young man will, after going through the stage of hunting, become more humane after the "thoughtless age of boyhood" and abstain from killing animals. He also realizes fishing is a moral-declining activity. People's interest or thirst for fishing starts from one's instinct, which "revives from time to time" and "belongs to the lower orders of creation" (Thoreau, 2004:206). In Thoreau's view, one has to understand and then inhibit the inner "animality" to kill and hunt in order to become a man of higher morality and spirituality, which also serves as the purpose of his keeping a vegetarian diet. He attributes his repugnance to animal food to his 
instinctual need and asserts that man's spiritual condition will be optimized through an abstinence from animal food.

The repugnance to animal food is not the effect of experience, but is an instinct. It appeared more beautiful to live low and fare hard in many respects; and though I never did so, I went far enough to please my imagination. I believe that every man who has ever been earnest to preserve his higher or poetic faculties in the best condition has been particularly inclined to abstain from animal food, and from much food of any kind." (2004:206)

Furthermore, Thoreau claims that extra spices into the dishes not only do detriments to one's imagination but also to the civilizations of mankind. He then identifies himself with the idea of mankind as a carnivorous animal and holds firmly that mankind will gradually refrain from eating animals.

Is it not a reproach that man is a carnivorous animal? True, he can and does live, in a great measure, by preying on other animals; but this is a miserable way. Whatever my own practice may be, I have no doubt that it is a part of the destiny of the human race, in its gradual improvement, to leave off eating animas, as surely as the savage tribes have left off eating each other when they came in contact with the more civilized.” (2004:207)

Apparently, Thoreau's abstinence from animal food is closely related to his aspiration for a higher spiritual life. To him, humanity to non-human animals is necessarily entailed by this kind of spiritual life. Thoreau goes on to ascribe a higher spiritual life to stoicism. Not only abstinence from animal food is necessary, but too much food or even a cup of coffee or tea would corrupt one's mind. To keep sober, he drinks water instead of wine because "water is the only drink for a wise man" while "wine is not a so noble a liquor". He is very much in favor of a simplistic diet as a way to nourish his spirituality. "I have been thrilled to think that I owed a mental perception to the commonly gross sense of taste, that I have been inspired through the palate, that some berries which I had eaten on a hillside had fed my genius" (Thoreau, 2004:209). As Barbara Darling-Smith asserts, "Thoreau was adamantly opposed to Christian forms of 'austerity': rather than bypassing our earthly needs for spiritual ends, we must learn to understand our animality and serve it in simple and healthy ways. Thoreau champions self-control and restraint in the name of the 'society in Nature': his exercise of self-mastery is a response to his membership in the broader ecological 'society"' (2007:175).

\section{Conclusion}

From what has been discussed above, we can come to the conclusion that not only does Thoreau view non-human animals as subjects possessing their own consciousness and sentience, he also regards a consummation of one's spirituality involves admitting and understanding of one's inner animality so as to inhibit his savage instinct to hunt or kill animals for food, on the grounds that animals are sentient to feel pain and sufferings and animal food is both unclean and degenerated. Therefore, Thoreau's humanity to non-human animals inspires and will inspire his modern readers to show more respect for non-human animals and lead them to aspire for higher laws in their spiritual development. To cite from Philip Cafaro, "As we strive to develop a strong and effective environmental ethics, I believe no thinker has more to offer than Henry Thoreau. He was one of the earliest and remains one of the strongest critics of anthropocentrism ... Perhaps even more important, Thoreau shows us how to lead flourishing lives while still treating nature with respect" (Cafaro 2004: 139). 


\section{References}

Buell, Lawrence (1995). The Environmental Imagination: Thoreau, Nature Writing, and the Formation of American Culture. Cambridge: Harvard University Press.

Cafaro, Philip (2004). Thoreau's Living Ethics: Walden and the Pursuit of Virtue. Athens: University of Georgia Press.

Darling-Smith, Barbara. ed (2007). Responsibility. Lanham: Lexington Books.

Foster, David R. (2009). Henry David Thoreau's Country: Journey through a Transformed Landscape. Cambridge: Harvard University Press.

Marx, Leo (1964). The Machine in the Garden: Technology and the Pastoral Ideal in America. New York: Oxford University Press.

Regan, Tom (2004). The Case for Animal Rights. Berkeley: University of California Press.

Salt, Henry S. (2000). Life of Henry David Thoreau. Ed. George Hendrick, Willene Hendrick and Fritz Oehlschlaeger. Urbana: University of Illinois Press.

Singer, Peter (2002). Animal Liberation. New York: Harper Collins Publishers.

Specq, François, Laura Dassow Walls, and Michel Granger eds. (2013). Thoreauvian Modernities: Transatlantic Conversations on an American Icon. Athens: University of Georgia Press.

Thoreau, Henry D. (2005). Bonds of Affection: Thoreau on Dogs and Cats, Henry David Thoreau. Ed. Wesley T. Mott. Amherst: University of Massachusetts Press, 2005

---. (2004). Walden: A Fully Annotated Edition. Ed. Jeffery S. Cramer. New Haven: Yale University Press.

---. (1974). The Correspondence of Henry David Thoreau. Ed. Walter Harding and Carl Bode. Westport: Greenwood Press.

---. (2014). The Illustrated "A Week on the Concord and Merrimack Rivers". Princeton: Princeton University Press.

Worster, Donald (1977). Nature's Economy: A History of Ecological Ideas. San Francisco: Sierra Club Books. 